\title{
CAPE promotes the expansion of human umbilical cord blood-derived hematopoietic stem and progenitor cells in vitro
}

\author{
LIU YiMing ${ }^{\dagger}, Z_{\text {ZHANG BoWen }}^{\dagger}$, ZHANG Jing, WANG SiHan, YAO HaiLei, HE LiJuan, \\ CHEN Lin, YUE Wen, LI YanHua* \& PEI XueTao*
}

Stem Cell and Regenerative Medicine Lab, Beijing Institute of Transfusion Medicine, Beijing 100850, China

Received July 29, 2013; accepted September 12, 2013; published online January 21, 2014

\begin{abstract}
Due to the low number of collectable stem cells from single umbilical cord blood (UCB) unit, their initial uses were limited to pediatric therapies. Clinical applications of UCB hematopoietic stem and progenitor cells (HSPCs) would become feasible if there were a culture method that can effectively expand HSPCs while maintaining their self-renewal capacity. In recent years, numerous attempts have been made to expand human UCB HSPCs in vitro. In this study, we report that caffeic acid phenethyl ester (CAPE), a small molecule from honeybee extract, can promote in vitro expansion of HSPCs. Treatment with CAPE increased the percentage of HSPCs in cultured mononuclear cells. Importantly, culture of CD $34^{+} \mathrm{HSPCs}$ with CAPE resulted in a significant increase in total colony-forming units and high proliferative potential colony-forming units. Burst-forming unit-erythroid was the mostly affected colony type, which increased more than 3.7 -fold in $1 \mu \mathrm{g} \mathrm{mL}^{-1}$ CAPE treatment group when compared to the controls. CAPE appears to induce HSPC expansion by upregulating the expression of SCF and HIF1- $\alpha$. Our data suggest that CAPE may become a potent medium supplement for in vitro HSPC expansion.
\end{abstract}

hematopoietic stem and progenitor cells, caffeic acid phenethyl ester, expansion

Citation: Liu YM, Zhang BW, Zhang J, Wang SH, Yao HL, He LJ, Chen L, Yue W, Li YH, Pei XT. CAPE promotes the expansion of human umbilical cord blood-derived hematopoietic stem and progenitor cells in vitro. Sci China Life Sci, 2014, 57: 188-194, doi: 10.1007/s11427-014-4611-8

Transplantation of hematopoietic stem cells and progenitor cells (HSPCs) has been used for many years to treat various malignant and non-malignant hematologic diseases. The infused HSPCs can replace and reconstitute the hematopoietic and immune systems in patients subjected to chemotherapy or radiotherapy. In the last decade, umbilical cord blood (UCB) becomes a new resource of HSPCs for allogeneic transplantation [1]. UCB transplantation shows many advantages, including elimination of donor risk, rapid availability, low risk of infection, and preservation of graft-versus-leukemia effect, despite the relatively low risk of graft-versus-host disease. Due to the low number of collectable stem cells from single UCB units, the initial uses

$\uparrow$ Contributed equally to this work

*Corresponding author (email: shirlylyh@126.com; peixt@nic.bmi.ac.cn) were limited to pediatric therapies. Clinical applications of UCB HSPCs would become feasible if there were a culture method that can effectively expand HSPCs while maintaining their self-renewal capacity.

In recent years, numerous attempts have been made to expand human UCB HSPCs in vitro [2,3]. Most ex vivo cultures of human HSPCs use cytokine mixtures in serum-free medium that includes SCF, TPO, IL-3, IL-6 and Flt3-L [4]. The manipulation of some signaling pathways such as Notch and Wnt has also shown effectiveness for $e x$ vivo expansion of HSPCs [5]. Several labs explored to expand HSPCs with aryl hydrocarbon receptors, copper chelators, stromal support, and automated continuous perfusion of culture systems or "bioreactors" [3,6-8]. Over-expression of transcription factors, such as SALL4, HOXB4, can 
also increase the number of HSPCs in vitro [9,10]. Although in vitro culture method for expansion of HSPCs has been improved, it still needs to be optimized to obtain more transplantable HSPCs.

Caffeic acid phenethyl ester (CAPE) is an active component of propolis from honeybee with various beneficial properties, such as anti-inflammatory and antioxidant effects [11]. Increasing evidence suggests that CAPE can exert protective effect against ischemia/reperfusion (I/R) injury occurred in many tissues [12-14]. Wang has reported that CAPE treatment induced the upregulation of kit ligand (SCF) and heme oxygenase-1 (HO-1) gene expression in HUVECs [15]. Both SCF and HO-1 play important roles in the regulation of HSPC function [16]. Thus, we speculate that CAPE may also play a role in the in vitro proliferation of HSPCs.

In this study, we report that CAPE, a small molecule from honeybee extract, can promote in vitro UCB HSPC expansion, and CAPE induces HSPC expansion probably through upregulating the expression of SCF and HIF1- $\alpha$. Our data suggest that CAPE may become a potent medium supplement for in vitro HSPC expansion.

\section{Materials and methods}

\subsection{The isolation of MNCs and $\mathrm{CD34}^{+}$cells}

MNCs were isolated from the fresh UCB samples using lymphocyte separation medium in $1.077 \mathrm{~g} \mathrm{~mL}^{-1}$ (TBD sciences, China). The cell suspension was centrifuged at $600 \times g$ for $25 \mathrm{~min}$, and then MNCs band at the interface was isolated, and washed twice with PBS (Gibco, USA). The $\mathrm{CD}_{3}{ }^{+}$cells were isolated from MNCs using the CD34 ${ }^{+}$ Microbead kit (MiltenyiBiotec, Germany) according to the manufacturer's protocol.

\subsection{In vitro culture}

The $\mathrm{CD}^{+} 4^{+}$cells $\left(2 \times 10^{5}\right.$ cells/well $)$ or MNCs $\left(1 \times 10^{6}\right.$ cells/well) were cultured in 24-well plates (Costar tissue-culture treated polystyrene, Corning, USA) in HSPC expansion medium (StemSpan SFEM, StemCell Technologies, Canada). The medium was supplemented with several cytokines (Peprotech, USA), including SCF (25 ng mL $\mathrm{mL}^{-1}$ ), TPO (10 ng mL $\left.{ }^{-1}\right)$, IL-3 (20 ng mL $\left.{ }^{-1}\right)$, IL-6 (10 ng mL $\left.{ }^{-1}\right)$. CAPE was added into the culture medium at different concentrations $\left(0.1 \mu \mathrm{g} \mathrm{mL}^{-1}, 1 \mu \mathrm{g} \mathrm{mL}^{-1}\right)$. Cells were cultured at $37^{\circ} \mathrm{C}$ in $5 \% \mathrm{CO}_{2}$.

\subsection{Flow cytometry}

Cells were washed twice in PBS containing 2\% FBS. The cells were incubated with isotypic antibodies or the indicated antibodies in the dark for $40 \mathrm{~min}$ at $4{ }^{\circ} \mathrm{C}$. Next, the cells were washed three times with PBS and suspended in $0.4 \mathrm{~mL}$ PBS for analysis. Live cells were determined by 7-AAD (BD Biosciences, USA) exclusion. Flow cytometry analysis was performed using BD FACS Aria (BD Biosciences). The data were analyzed using BD FACSDiva software. The following antibodies were used: CD34-PE (eBioscience, USA), CD38-APC (eBioscience).

\subsection{Cell apoptosis and survival analysis}

The $\mathrm{CD} 34^{+}$cells were washed in PBS and apoptosis was evaluated as the percentage of Annexin V-positive cells using apoptosis kit (Invitrogen, USA) according to the manufacturer's protocol.

\subsection{Colony-forming units (CFU) assay}

Cultured $\mathrm{CD} 34^{+}$cells $\left(5 \times 10^{2}\right.$ cells/well $)$ or MNCs $\left(4 \times 10^{3}\right.$ cells/well) at day 7 were plated in a methylcellulose-based medium (MethoCult H4434, StemCell Technologies). Each experiment was performed in triplicate. Two weeks after plating, CFU were counted under an inverted microscope and identified according to morphological criteria. High proliferative potential colony-forming units (HPP-CFU) were counted at three weeks after plating.

\subsection{Quantitative RT-PCR}

Cells were lysed and total RNA was isolated by Trizol Reagent (Invitrogen), followed by reverse transcription of $1 \mu \mathrm{g}$ total RNA with the reverse transcriptase M-MLV (Takara, Japan) using oligo(dT) primers. Quantitative RT-PCR reactions were performed with SYBR Green real time PCR Master Mix (TOYOBO, Japan) on Bio-Rad iQ5 System (Bio-Rad, USA). The expression of each gene was normalized to GAPDH gene expression and three replicates were analyzed for each condition. The primer sequences for quantitative RT-PCR were listed in Supporting Infromation (Table S1 in Supporting Information).

\subsection{Statistic analysis}

All values were shown as mean \pm SD. The statistic significance between two groups was determined by Student's $t$-test.

\section{Results}

\subsection{Treatment with CAPE increases the percentage of HSPCs}

To evaluate whether CAPE (Figure 1A) has the capability to expand HSPCs, we isolated UCB-derived MNCs and placed them in medium with cytokines alone or cytokines plus 0.1 or $1 \mu \mathrm{g} \mathrm{mL}^{-1} \mathrm{CAPE}$ for $7 \mathrm{~d}$. The increase in total 

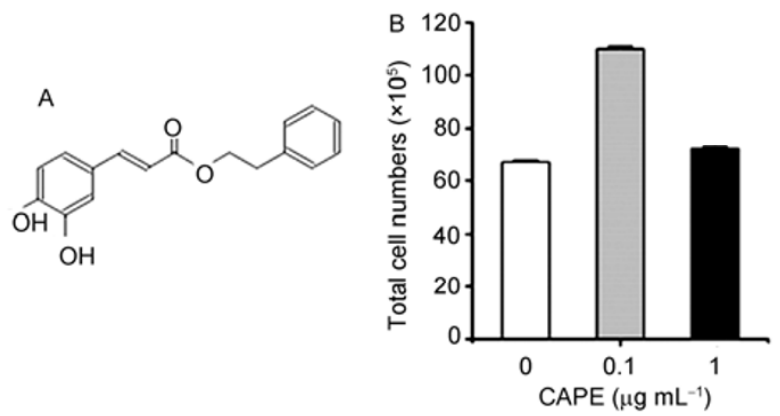

Figure 1 A, The structure of CAPE. B, The total cell numbers of MNCs growing at different CAPE concentrations for $7 \mathrm{~d}$. cell numbers was not significantly different between the cytokines alone or cytokines plus $1 \mu \mathrm{g} \mathrm{mL}^{-1} \mathrm{CAPE}$ group (Figure 1B). Then we used flow cytometer to analyze the percentage of HSPCs in cultured cells. The percentage of $\mathrm{CD} 34^{+}$and $\mathrm{CD} 34^{+} \mathrm{CD} 38^{-}$cells was approximately $1.5 \%$ and $0.2 \%$ in primary UCB MNCs (Figure $2 \mathrm{Aa}$ ). Both cytokines and cytokines plus CAPE treatments induced significant increase of the proportion of HSPCs in cultured MNCs (Figure $2 \mathrm{Ab}-\mathrm{d}$ ). Much higher percentage of $\mathrm{CD} 34^{+}$or $\mathrm{CD} 34^{+} \mathrm{CD} 38^{-}$cells was observed in cultures treated with cytokines plus $1 \mu \mathrm{g} \mathrm{mL}^{-1} \mathrm{CAPE}$ (Figure $2 \mathrm{Ad}$ ). The numbers of $\mathrm{CD} 34^{+}$or $\mathrm{CD} 34^{+} \mathrm{CD} 38^{-}$cells also increased in cultured
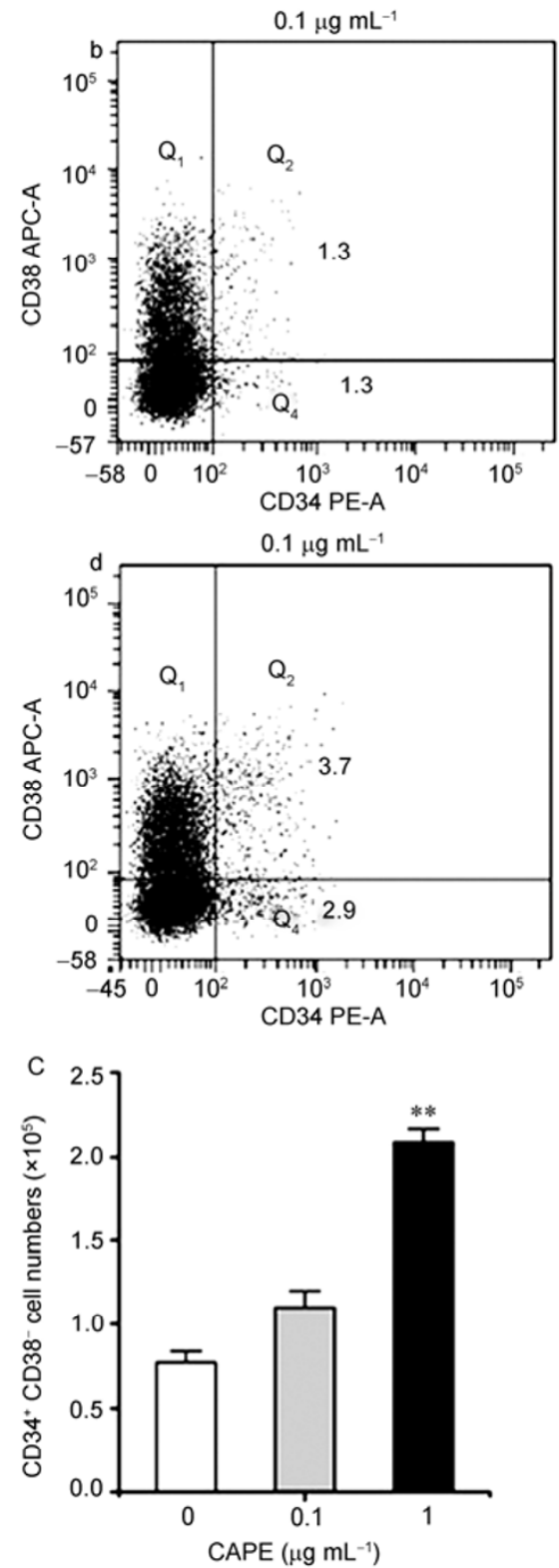

Figure 2 The detection of $\mathrm{CD} 34^{+}$and $\mathrm{CD} 34^{+} \mathrm{CD} 38^{-}$cells in cultured MNCs at different CAPE concentrations. A, The percentage of CD34 ${ }^{+}$and $\mathrm{CD} 34^{+} \mathrm{CD} 38^{-}$cells in primary MNCs (a, $0 \mathrm{~d}$; just separated from cord blood) and MNCs cultured for $7 \mathrm{~d}$ (b-d, with different CAPE concentrations). B, The $\mathrm{CD} 34^{+}$cell numbers were calculated in the cultured MNCs with CAPE treatment at different concentrations. $\mathrm{C}$, The $\mathrm{CD} 34^{+} \mathrm{CD} 38^{-}$cell numbers were calculated in the cultured MNCs with CAPE treatment at different concentrations. **, $P \leqslant 0.01 \mathrm{vs.} 0 \mu \mathrm{g} \mathrm{mL}^{-1}$. 
MNCs with cytokines plus $1 \mu \mathrm{g} \mathrm{mL} \mathrm{mL}^{-1} \mathrm{CAPE}$ (Figure $2 \mathrm{~B}$ and C). These data indicated that treatment with CAPE promoted the in vitro expansion of UCB HSPCs.

\subsection{Treatment with CAPE increases the numbers of CFU}

To further evaluate the effect of CAPE on HSPC proliferation, we isolated UCB CD $34^{+}$cells using miniMACS selection system and cultured them with cytokines alone or cytokines plus CAPE for $7 \mathrm{~d}$. Compared with control group, the survival rate of these cultured $\mathrm{CD} 34^{+}$cells was not significantly altered with CAPE treatment at $0.1 \mu \mathrm{g} \mathrm{mL} \mathrm{g}^{-1}$ and showed a slight decrease with CAPE treatment at $1 \mu \mathrm{g} \mathrm{mL}^{-1}$ (Figure 3). However, the content of hematopoietic progenitor cells was significantly increased with CAPE treatment. In CFU assays (Figure 4A), culture of $\mathrm{CD} 34^{+}$cells with 0.1 or $1 \mu \mathrm{g} \mathrm{mL}^{-1} \mathrm{CAPE}$ resulted in a dose-dependent increase in burst-forming unit-erythroid (BFU-E) and colony forming unit-granulocyte, erythrocyte, megakaryocyte, macrophage (CFU-GEMM) (Figure 4B). Interestingly, BFU-E was the most affected colony type, increasing more than 3.7-fold in cells treated with $1 \mu \mathrm{g} \mathrm{mL} \mathrm{mL}^{-1} \mathrm{CAPE}$ when comparing to the control group (Figure 4B). For total CFU, a 2.6-fold or 3.1-fold increase in 0.1 or $1 \mu \mathrm{g} \mathrm{mL}{ }^{-1}$ CAPE-treated cells was observed when compared with the control group (Figure $4 \mathrm{C}$ ). The numbers of HPP-CFU were also markedly increased with CAPE treatment (Figure 4D).

\subsection{CAPE upregulates the expression of SCF and HIF-1a}

To investigate the mechanism by which CAPE increased the numbers of HSPC, we performed Q-PCR analysis to detect the expression of proliferation and apoptosis-related genes with cDNA from cultured MNCs. Wang has reported that CAPE treatment induced the upregulation of kit ligand (SCF) and HO-1 in HUVECs [15]. SCF plays a critical role for early phases of hematopoiesis, and facilitates HSPC proliferation and survival [16]. Our results showed that CAPE significantly upregulated the expression of SCF. The increased secretion of SCF protein was also observed in CAPE-treated cells (data not shown). HO-1 is a critical regulator of the stress response in HSPCs via controlling the level of its substrates (heme) and bioactive products [17]. The expression of HO-1 was also significantly upregulated by CAPE. Hypoxia-inducible factor- $1 \alpha(\mathrm{HIF}-1 \alpha)$ is required for long-term HSC maintenance and can synergize with glucocorticoids to promote BFU-E progenitor self-renewal $[18,19]$. We also found that the expression level of HIF-1 $\alpha$ was increased by CAPE treatment. In addition, there was a slight increase in the expression of BCL-2 gene in the cells treated with $1 \mu \mathrm{g} \mathrm{mL}^{-1} \mathrm{CAPE}$. These results suggested that increased expression of SCF and HIF-1 $\alpha$ promoted the expansion of HSPCs.

\section{Discussion}

HSPC is probably the most extensively studied somatic stem cell. It has the capability for self-renewal. It can also differentiate into all types of mature blood cells. Methods to expand HSPCs are always accompanied with their differentiation. However, it is still difficult to obtain sufficient numbers of HSPCs for transplantation. For a broader clinical application, additional studies are necessary for a deeper understanding of the cell biology of HSPCs, the microenvironment that nurtures these cells, and finding small molecules that stimulate HSPC expansion.

In this study, we found that a small molecule, CAPE, plays a regulatory role in HSPC in vitro proliferation. CAPE, a honeybee extract, exerts protective effect in I/R injury. It can minimize radiation-induced hearing damage in rats [20]. Moreover, CAPE has been found to be a protective agent against chemotherapy-induced and radiotherapy-induced toxicity [21]. Further study suggested that CAPE can induce the expression of HIF- $1 \alpha$ protein and concomitantly trans-
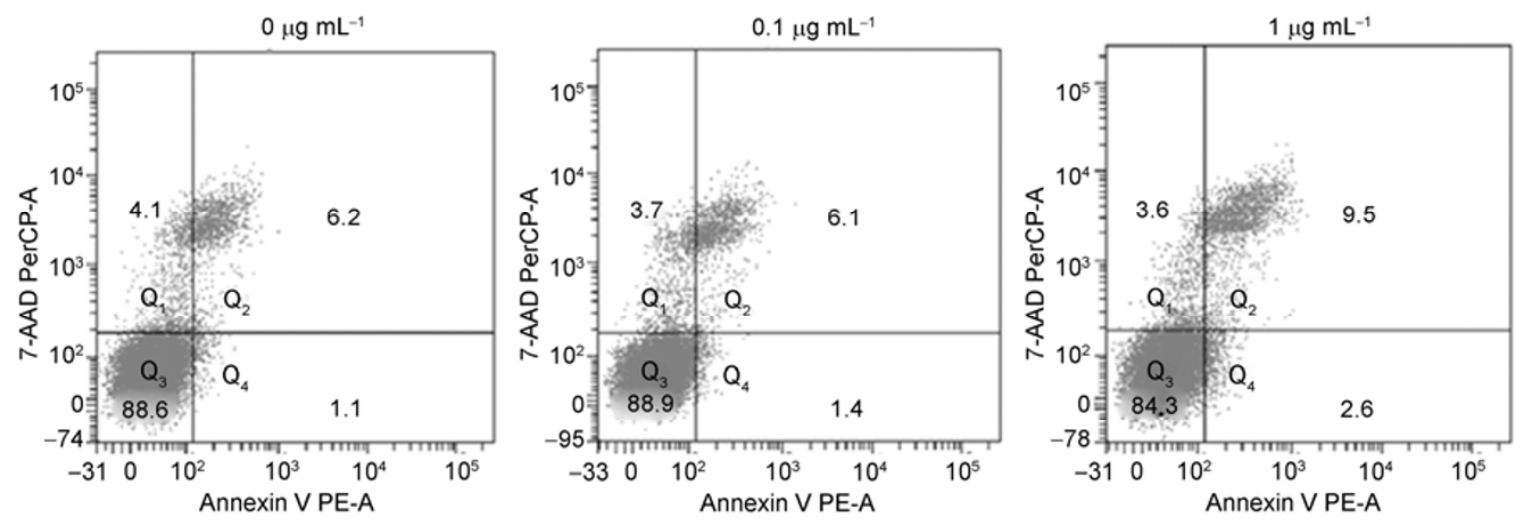

Figure 3 Survival rate analysis of MNCs growing for $7 \mathrm{~d}$ at different CAPE concentrations. The MNCs were stained with 7-AAD and Annexin V. Viable cells are in the lower left quadrant. 

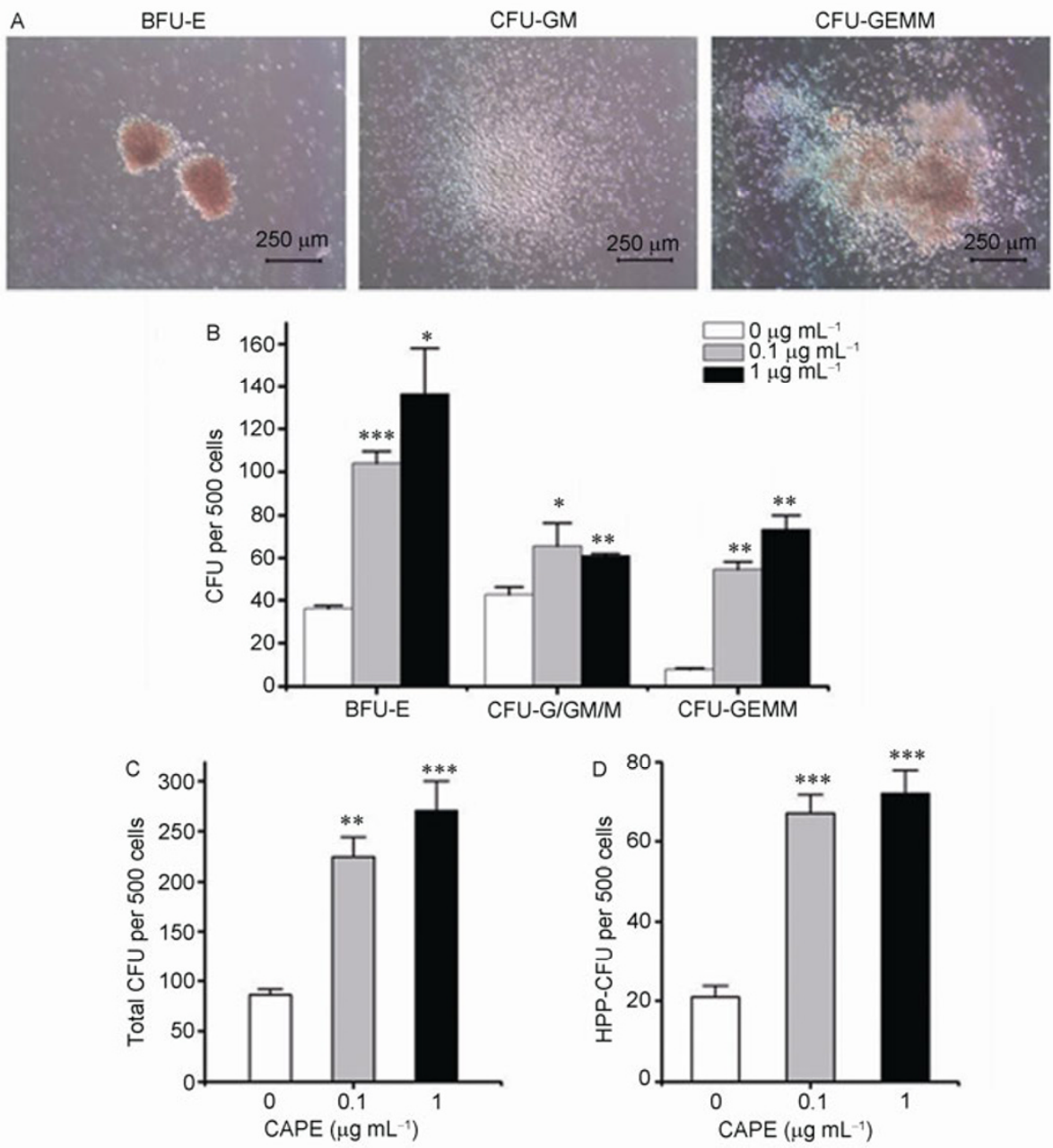

Figure 4 The $\mathrm{CFU}$ assays of $\mathrm{CD} 34^{+}$cells cultured for $7 \mathrm{~d}$ at different CAPE concentrations. A, The colony morphology of BFU-E, CFU-GM and CFU-GEMM. B, The colony numbers of BFU-E, CFU-G/GM/M and CFU-GEMM. C, The total CFU numbers were calculated. D, The HPP-CFU numbers were counted. CFU-GM: colony forming unit-granulocyte and macrophage; CFU-G/GM/M: colony forming unit-granulocyte/granulocyte and macrophage/megakaryocyte. *, $P \leqslant 0.05 ; * *, P \leqslant 0.01$ vs. $0 \mu \mathrm{g} \mathrm{mL}{ }^{-1}$.

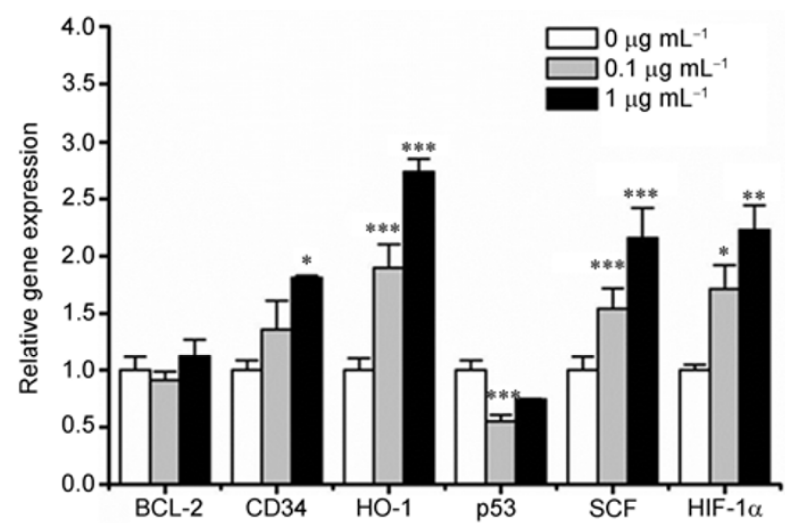

Figure 5 Quantitative PCR analysis of the expression levels of proliferation and apoptosis-related genes in MNCs cultured for 7 days with different concentrations of CAPE. $* P \leqslant 0.05$; **, $P \leqslant 0.01$ vs. $0 \mu \mathrm{g} \mathrm{mL} L^{-1}$.

activate the HIF-1 target genes, such as vascular endothelial growth factor and heme oxygenase-1 (HO-1), which play a protective role in I/R injury [21]. By using gene chip analysis, Wang reported that the expression levels of SCF and HO-1 genes were significantly upregulated in HUVECs. These genes play critical roles in HSPC proliferation and survival. Thus, we postulated that CAPE might function on HSPCs. We first evaluated its role on the survival of UCB MNCs. CAPE at low concentration levels $\left(0.1 \mu \mathrm{g} \mathrm{mL}^{-1}\right.$ or 1 $\mu \mathrm{g} \mathrm{mL}^{-1}$ ) showed little or slight effect on the survival rate of total nuclear cells. When the concentration of CAPE in medium reached $5 \mu \mathrm{g} \mathrm{mL} \mathrm{m}^{-1}$, it induced the reduction of the total cell numbers compared to the control group (data not shown). CAPE treatment at low concentration $\left(0.1 \mu \mathrm{g} \mathrm{mL}^{-1}\right.$ and $1 \mu \mathrm{g} \mathrm{mL}{ }^{-1}$ ) increased the numbers of $\mathrm{CD}^{+} 4^{+}$or $\mathrm{CD} 34^{+} \mathrm{CD} 38^{-}$cell in cultured UCB MNCs. The similar results were also seen in CFU assays (data not shown). These data suggested that CAPE might be used as a supplement in HSPC culture medium. We then isolated UCB CD $34^{+}$cells and cultured them in medium with cytokines plus CAPE at different concentrations. Similarly, low concentration of 
CAPE $\left(0.1 \mu \mathrm{g} \mathrm{mL}^{-1}\right)$ did not affect the apoptosis rate of cultured CD $34^{+}$cells. However, CAPE at $5 \mu \mathrm{g} \mathrm{mL}{ }^{-1}$ showed low cytotoxicity in cultured hematopoietic cells (data not shown). It has been reported that CAPE exerted the maximum cytoprotection in HUVECs against menadione-caused oxidative injury at $5 \mu \mathrm{g} \mathrm{mL}^{-1}$ and it produced cytotoxicity at $15 \mu \mathrm{g} \mathrm{mL}^{-1}$ [10]. These data suggested that different kinds of cells responded to different levels of CAPE in different ways. On the other hand, CAPE might increase the survival rate of cultured $\mathrm{CD} 34^{+}$cells under stress. In a normal culture condition, CAPE-treated $\mathrm{CD} 34^{+}$cells exhibited increased colony-forming capacity. Interestingly, BFU-E was the most obviously affected colony type, increasing more than 3.7-fold in cells treated with $1 \mu \mathrm{g} \mathrm{mL}^{-1}$ CAPE compared with the control group. We found that some genes (SCF, HIF-1 $\alpha$ and HO-1) are significantly upregulated by CAPE in cultured UCB cells, which might be the mechanism for CAPE to expand HSPCs. SCF, the most important cytokine for HSPC self-renewal, therefore is crucial to UCB HSPC expansion ex vivo. HIF-1 $\alpha$, a transcription factor, plays a pivotal role in cellular adaption to hypoxia. It has been reported that hypoxia and upregulation of HIF-1 $\alpha$ expression enhanced the proliferation of UCB HSPCs in vitro [22]. HO-1, a target gene of HIF-1 $\alpha$, also exerts the important role in the regulation of HSPC function. However, more work need to be done to further evaluate the function of CAPE-treated HSPCs, especially under stress conditions. For example, Wang's work showed that modification of the catechol ring of CAPE by introducing fluorine at various positions resulted in dramatic changes in cytoprotective activity [23]. Thus, it might be worth evaluating the role of CAPE derivatives on HSPC expansion under normal or stress culture condition.

In conclusion, CAPE, the small molecule from honeybee extract, can promote HSPC expansion in vitro. The mechanism of CAPE-induced HSPC expansion appears to involve upregulation of the expression of SCF, HIF-1 $\alpha$, and HO-1. Our data suggest that CAPE might become a new and potent medium supplement for in vitro HSPC expansion.

This work was supported by the National High Technology Research and Development Program of China (2013AA020107), National Basic Research Program of China (2011CB964804) and National Natural Science Foundation of China (31101040).

1 Barker JN, Weisdorf DJ, DeFor TE, Blazar BR, McGlave PB, Miller JS, Verfaillie CM, Wagner JE. Transplantation of 2 partially HLA-matched umbilical cord blood units to enhance engraftment in adults with hematologic malignancy. Blood, 2005, 105: 1343-1347

2 Zhang CC, Kaba M, Iizuka S, Huynh H, Lodish HF. Angiopoietin-like 5 and IGFBP2 stimulate ex vivo expansion of human cord blood hematopoietic stem cells as assayed by NOD/SCID transplantation. Blood, 2008, 111: 3415-3423

3 Boitano AE, Wang J, Romeo R, Bouchez LC, Parker AE, Sutton SE, Walker JR, Flaveny CA, Perdew GH, Denison MS, Schultz PG, Cooke MP. Aryl hydrocarbon receptor antagonists promote the ex- pansion of human hematopoietic stem cells. Science, 2010, 329: 1345-1348

4 Murray LJ, Young JC, Osborne LJ, Luens KM, Scollay R, Hill BL. Thrombopoietin, flt3, and kit ligands together suppress apoptosis of human mobilized CD $34^{+}$cells and recruit primitive CD $34^{+}$Thy $-1^{+}$ cells into rapid division. Exp Hematol, 1999, 27: 1019-1028

5 Lu J, Pompili VJ, Das H. Hematopoietic stem cells: ex-vivo expansion and therapeutic potential for myocardial ischemia. Stem Cells and Cloning; Advances and Applications, 2010, 3: 57-68

6 Ferreira MS, Jahnen-Dechent W, Labude N, Bovi M, Hieronymus T, Zenke M, Schneider RK, Neuss S. Cord blood-hematopoietic stem cell expansion in 3D fibrin scaffolds with stromal support. Biomaterials, 2012, 33: 6987-6997

7 Peled T, Landau E, Mandel J, Glukhman E, Goudsmid NR, Nagler A, Fibach E. Linear polyamine copper chelator tetraethylenepentamine augments long-term ex vivo expansion of cord blood-derived CD34 ${ }^{+}$ cells and increases their engraftment potential in NOD/SCID mice. Exp Hematol, 2004, 32: 547-555

8 da Silva CL, Gonçalves R, Crapnell KB, Cabral JM, Zanjani ED, Almeida-Porada G. A human stromal-based serum-free culture system supports the ex vivo expansion/maintenance of bone marrow and cord blood hematopoietic stem/progenitor cells. Exp Hematol, 2005, 33: 828-835

9 Yang J, Aguila JR, Alipio Z, Lai R, Fink LM, Ma Y. Enhanced self-renewal of hematopoietic stem/progenitor cells mediated by the stem cell gene Sall4. J Hematol Oncol, 2011, 4: 38

10 Amsellem S, Pflumio F, Bardinet D, Izac B, Charneau P, Romeo PH, Dubart-Kupperschmitt A, Fichelson S. Ex vivo expansion of human hematopoietic stem cells by direct delivery of the HOXB4 homeoprotein. Nat Med, 2003, 9: 1423-1427

11 Dos Santos JS, Monte-Alto-Costa A. Caffeic acid phenethyl ester improves burn healing in rats through anti-inflammatory and antioxidant effects. J Burn Care Res, 2013, 34: 682-8

12 Teke Z, Bostanci EB, Yenisey C, Sacar M, Simsek NG, Akoglu M. Caffeic acid phenethyl ester alleviates mesenteric ischemia/reperfusion injury. J Invest Surg, 2012, 25: 354-6513

13 Roso NC, Correa RR, Castiglia YM, Carvalho LR, Scatena LM, de Souza AV, de Oliveira CC, Vianna PT. Caffeic acid phenethyl ester effects in the kidney during ischemia and reperfusion in rats anesthetized with isoflurane. Transplant Proc, 2012, 44: 1211-1213

14 Kart A, Cigremis Y, Ozen H, Dogan O. Caffeic acid phenethyl ester prevents ovary ischemia/reperfusion injury in rabbits. Food Chem Toxicol, 2009, 47: 1980-1984

15 Wang XY. Amelioration of oxidative stress in human endothelial cells by caffeic acid phenethyl ester (CAPE) and fluorinated derivatives (FCAPE) and pharmacokinetic characterization of CAPE and FCAPE in rats. Dissertation for Doctoral Degree. Texas: The University of Texas at Austin, 1974

16 Gabbianelli M, Pelosi E, Montesoro E, Valtieri M, Luchetti L, Samoggia P, Vitelli L, Barberi T, Testa U, Lyman S, Peschle C. Multi-level effects of flt3 ligand on human hematopoiesis: Expansion of putative stem cells and proliferation of granulomonocyticprogenitors/monocytic precursors. Blood, 1995, 86: 1661-1670

17 Cao YA, Wagers AJ, Karsunky H, Zhao H, Reeves R, Wong RJ, Stevenson DK, Weissman IL, Contag CH. Heme oxygenase-1 deficiency leads to disrupted response to acute stress in stem cells and progenitors. Blood, 2008, 112: 4494-4502

18 Suda T, Takubo K, Semenza GL. Metabolic regulation of hematopoietic stem cells in the hypoxic niche. Cell stem cell, 2011, 9: 298-310

19 Flygare J, Rayon Estrada V, Shin C, Gupta S, Lodish HF. HIF-1 $\alpha$ synergizes with glucocorticoids to promote BFU-E progenitor self-renewal. Blood, 2011, 117: 3435-3444

20 Mansour HH, Tawfik SS. Early treatment of radiation-induced heart damage in rats by caffeic acid phenethyl ester. Eur J Pharmacol, 2012, 692: 46-51

21 Choi D, Han J, Lee Y, Choi J, Han S, Hong S, Jeon H, Kim YM, Jung Y. Caffeic acid phenethyl ester is a potent inhibitor of hifprolyl hydroxylase: Structural analysis and pharmacological implication. J 
Nutr Biochem, 2010, 21: 809-817

22 Roy S, Tripathy M, Mathur N, Jain A, Mukhopadhyay A. Hypoxia improves expansion potential of human cord blood-derived hematopoietic stem cells and marrow repopulation efficiency. Eur J Haematol, 2012, 88: 396-405
23 Wang X, Stavchansky S, Kerwin SM, Bowman PD. Structureactivity relationships in the cytoprotective effect of caffeic acid phenethyl ester (CAPE) and fluorinated derivatives: Effects on heme oxygenase-1 induction and antioxidant activities. Eur J Pharmacol, 2010, 635: 16-22

Open Access This article is distributed under the terms of the Creative Commons Attribution License which permits any use, distribution, and reproduction in any medium, provided the original author(s) and source are credited.

\section{Supporting Information}

\section{Table S1 Primer list}

The supporting information is available online at life.scichina.com and link.springer.com. The supporting materials are published as submitted, without typesetting or editing. The responsibility for scientific accuracy and content remains entirely with the authors. 